\title{
ASSESSMENT OF DERMATOLOGY LIFE QUALITY INDEX IN HAND ECZEMA
}

\author{
Abhinaya Reddy1, Adikrishnan Swaminathan², Mythreyi Rajendran³, Anandan Subramaniam4, Sudha Rangarajan ${ }^{5}$, \\ Mahalakshmi Veeraraghavan ${ }^{6}$
}

${ }^{1}$ M. D., Department of Dermatology, Venereology and Leprosy.

${ }^{2}$ Associate Professor, DDVL, DNB, MNAMS.

${ }^{3}$ Postgraduate Student, Department of Dermatology.

${ }^{4}$ Professor and Dean, $M D, D D, P G D H A$.

5 Professor, DD, DNB, MNAMS.

${ }^{6}$ Professor, DD, DNB, MNAMS.

ABSTRACT

\section{BACKGROUND}

Eczema is a term derived from the Greek word $\varepsilon^{\prime} \kappa \zeta \varepsilon \mu \alpha$, meaning 'to boil.' Hand eczema is one of the most frequently seen diseases in dermatological practice causing emotional and physical distress. In this study, we assessed the impact of hand eczema severity on the quality of life by the Dermatology Life Quality Index scoring system.

\section{MATERIALS AND METHODS}

This is an observational study conducted in the Dermatology Outpatient Department, Sri Ramachandra University, Chennai. They were clinically evaluated with detailed history, complete physical examination and were asked to fill the questionnaires. Patients who fulfilled both the inclusion and exclusion criteria were included in this study after proper counselling and recording their consents.

\section{RESULTS}

A total number of 150 patients with hand eczema were taken up in this study. Most patients belonged to the age group of $51-60$ years followed by the age group of 51 - 60 years. Female preponderance was seen in this study. Wear and tear dermatitis was the commonest morphological type found. 55 patients had a moderate impact on the quality of life calculated by Dermatology Life Quality Index.

\section{CONCLUSION}

Hand eczema is a common disorder ranging from mild-to-severe, seen commonly in women and is the most common occupational skin disease. Wear and tear dermatitis is the most common morphological variant seen. Hand eczema has an impact in quality of life with loss of work days.

\section{KEYWORDS}

Hand Eczema, Occupational, Quality of Life.

HOW TO CITE THIS ARTICLE: Reddy A, Swaminathan A, Rajendran M, et al. Assessment of dermatology life quality index in hand eczema. J. Evolution Med. Dent. Sci. 2018;7(04):459-461, DOI: 10.14260/jemds/2018/102

\section{BACKGROUND}

Eczema is a term derived from the Greek word $\varepsilon^{\prime} \kappa \zeta \varepsilon \mu \alpha$ meaning 'to boil.' Hand eczema is one of the most frequently seen diseases in dermatological practice causing emotional and physical distress. ${ }^{1}$ It is a common skin disorder, which includes patients in whom lesions are largely confined to the hands with only minor involvement of other areas. ${ }^{2}$ The quality of life is impaired in patients with chronic, debilitating hand eczema. In this study, we assessed the impact of hand eczema severity on the quality of life by the Dermatology Life Quality Index scoring system.

\section{Objective}

To document and assess the demographics, clinical and quality of life of hand eczema in the outpatients attending Department of Dermatology, Venereology and Leprosy, Sri Ramachandra University.

'Financial or Other Competing Interest': None.

Submission 22-11-2017, Peer Review 07-01-2018,

Acceptance 12-01-2018, Published 22-01-2018.

Corresponding Author:

Dr. Adikrishnan Swaminathan, $6^{\text {th }}$ Block, 3D

Ceebros Park 2A, Radha Krishnan Salai,

Valasaravakkam, Chennai-600087.

E-mail: adi_krish@yahoo.com

DOI: $10.14260 /$ jemds $/ 2018 / 102$

\section{(c) $(1) \ominus$}

MATERIALS AND METHODS

\section{Study Design}

The present study was observational, descriptive, prospective and hospital-based study.

\section{Study Setting}

Sri Ramachandra Medical College, Chennai, a tertiary care hospital.

\section{Data Collection}

Subjects were screened for study participation from Outpatient Department of Dermatology, Venereology and Leprosy in Sri Ramachandra University. Patients above 16 years of age presenting with hand lesions suggestive of hand eczema were selected. Exclusion criteria included patients less than 16 years of age, those who had palmar psoriasis (previously proven by biopsy or who have other psoriatic skin lesions) and patients whose skin scraping for fungus was positive on potassium hydroxide mount. Following steps were followed: Documentation of clinical history, occupationclinical examination- assessing Dermatology Life Quality Index scoring- Statistical analysis.

\section{RESULTS}

A total number of 150 patients with hand eczema were taken up in this study. 41 patients belonged to the age group of 51 60 years followed by 38 patients belonging to the age group of 
51 - 60 years. Female preponderance was seen in this study. Wear and tear dermatitis was the commonest morphological type found. 55 patients had a moderate impact on the quality of life calculated by Dermatology Life Quality Index.
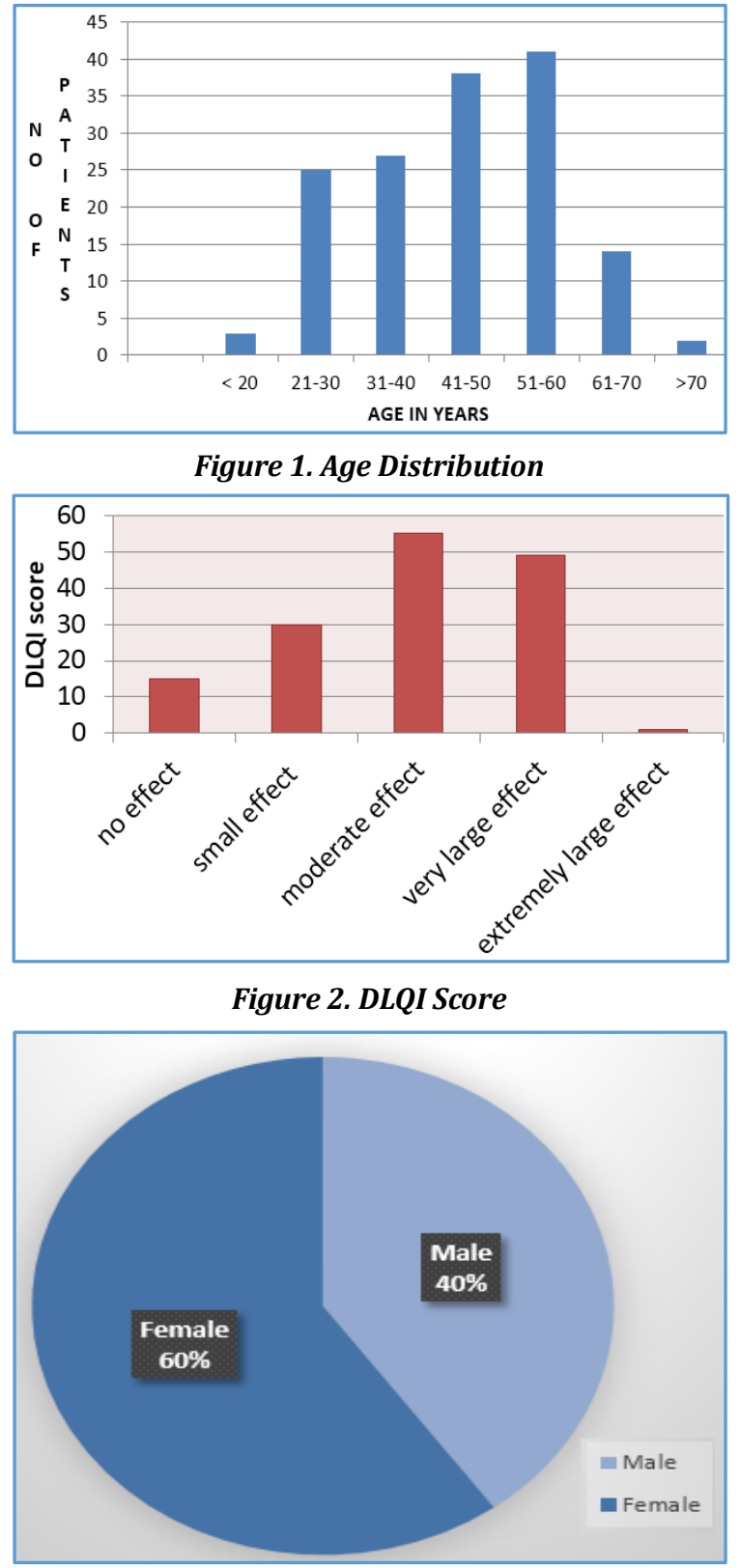

Figure 3. Sex Distribution

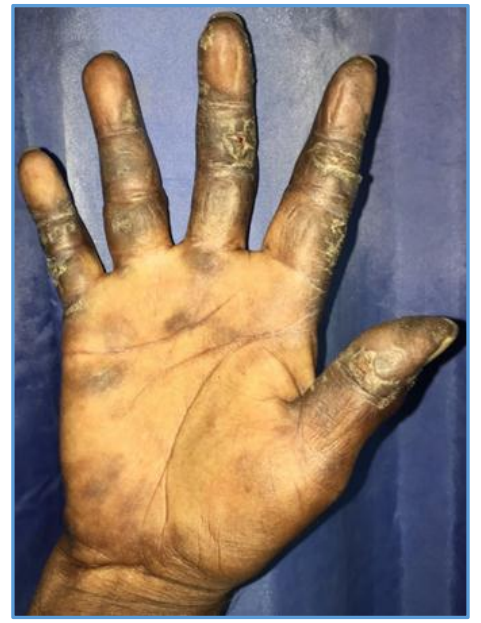

Picture 1. Hyperkeratotic Palmar Eczema

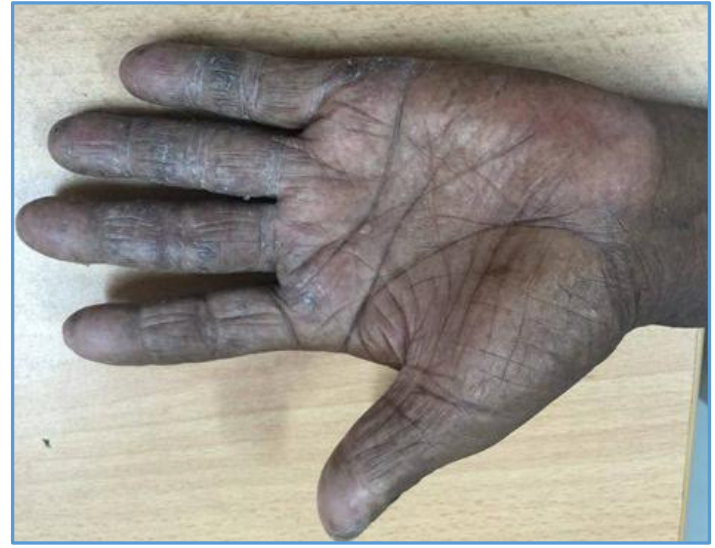

Picture 2. Wear and Tear Dermatitis

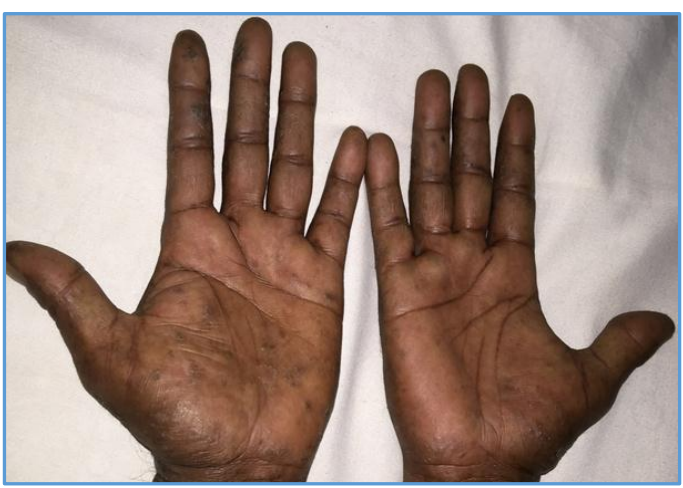

Picture 3. Pompholyx

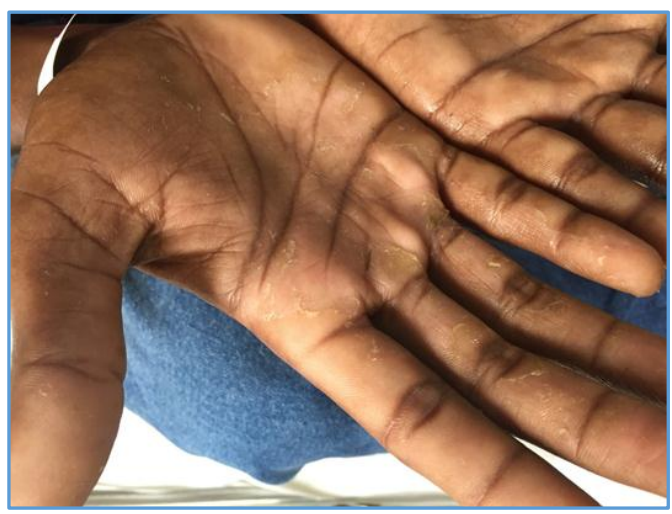

Picture 4. Keratolysis Exfoliativa

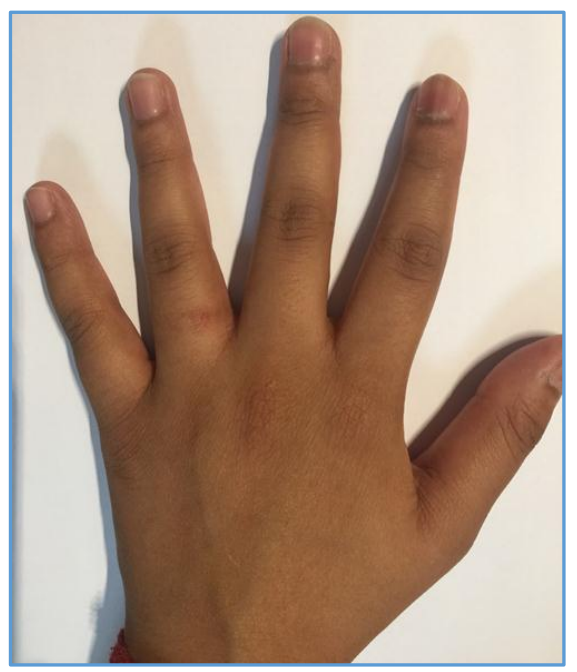

Picture 5. Ring Eczema 


\section{DISCUSSION}

Hand eczema can range from mild-to-severe and it affects women twice as often as men. ${ }^{3}$ In our study out of 150 patients, $60 \%$ were females and $40 \%$ were males showing female preponderance. The disease usually occurs before the age of 20 and it is also the most frequent occupational skin disease. ${ }^{4}$ In our study the average range of age was 51 - 60 in the present study, which is consistent with 50 - 59 found in the study in Vellore and differed from the $21-41$ yrs. in the Punjab study and the least number of patients were above 70 years accounting for $1.3 \%$. The prevalence of hand eczema varies according to the geographical region. The incidence of hand eczema was found to be $10.9 \%-15.8 \%$ in various studies, while in Indian dermatologic outpatient department of $5 \%-10 \%$ of allergic contact dermatitis patients. Hand involvement was seen in two-thirds of cases. ${ }^{5}$ In our study, hand eczema was most commonly found in housewives followed by cement workers and coolies. ${ }^{6}$ Hand eczema can be due to a number of causes both Exogenous (soaps, detergents, minor trauma, allergens, infections) and Endogenous (stress, atopy). ${ }^{2}$ In our study history of atopy was found in 52 patients in our study which was about 31.3\%, while the study in Vellore showed 23.9\%. Out of 150 patients 105 had a history of using Detergent soaps, which is $69.3 \%$ of the patients. 30 patients had history of smoking (20\%) and 20 patients had history of consumption of alcohol (13\%). Hand eczema is predominantly seen in cleaners, caterers, chefs, hairdressers, mechanics, surgeons, dentists, nurses, florists, machine operators, beauticians and construction workers. ${ }^{6}$ Eczemas can be acute or chronic. General features of acute eczema are exudation, blistering, crusting of the skin with illdemarcated erythema with papules and oedema. ${ }^{7}$ Chronic eczema is scalier with thickening and pigmentation with less vesicular eruptions. ${ }^{8}$ Painful fissuring can occur. Itching is a common symptom. Lichenification can be present, which is a leathery thickened condition secondary to repeated scratching. In our study out of 150 patients, most of the patients had hand eczema for a duration of 3 - 6 months $(25.3 \%)$ and 4 patients had the longest duration of more than 5 years. The morphological classification of hand eczema includes Apron eczema, Chronic acral dermatitis, Discoid eczema, Fingertip eczema, 'Gut' eczema, Hyperkeratotic palmar eczema, Pompholyx, Recurrent focal palmar peeling, Ring eczema, 'Wear and tear' dermatitis (dry palmar eczema) and other patterns (e.g. patchy vesiculosquamous). In our study, wear and tear dermatitis was the commonest morphological type found in 103 patients out of 150 patients, which was also found in Ujwala Priya Charan et al study done in Vellore followed by chronic acral dermatitis and fingertip eczema. ${ }^{9}$ Nail changes were seen in 10 patients, which was $6.66 \%$ of the total patients presenting with hand eczema. In the present study 47 patients reported a loss of work
(31.33\%), whereas in the study in Vellore only 13 patients reported a loss of work (27.7\%). 55 patients had a moderate impact on the quality of life calculated by Dermatology Life Quality Index. The average DLQI score was 8.26 which was similar with the study in Vellore, 9.54 and 8.68 in Birjand Iran, but differed from 6.22 in Punjab, Iran 14.8 and Denmark 6.0 .

\section{CONCLUSION}

Hand eczema is a common disorder ranging from mild-tosevere, seen commonly in women and is the most common occupational skin disease. Wear and tear dermatitis is the most common morphological variant seen. Hand eczema has an impact in quality of life with loss of work days.

\section{REFERENCES}

[1] Charan UP, Peter CVD, Pulimood SA. Impact of hand eczema severity on quality of life. Indian dermatology Online Journal 2013;4(2):102-5.

[2] Mortz CG, Lauritsen JM, Bindslev-Jensen C, et al. Prevalence of atopic dermatitis, asthma, allergic rhinitis and hand and contact dermatitis in adolescents. The Odense Adolescence Cohort Study on Atopic Diseases and Dermatitis. British Journal of Dermatology 2001;144(3):523-32.

[3] Thyssen JP, Johansen JD, Linneberg A, et al. The epidemiology of hand eczema in the general population - Prevalence and main findings. Contact Dermatitis 2010;62(2):75-87.

[4] Meding B, Swanbeck G. Occupational hand eczema in an industrial city. Contact Dermatitis 1990;22(1):1323.

[5] Yokota M, Maibach HI. Moisturizer effect on irritant dermatitis: an overview. Contact Dermatitis 2006;55(2):65-72.

[6] Uter W, Pfahlberg A, Gefeller O, et al. Prevalence and incidence of hand dermatitis in hairdressing apprentices: results of the POSH study. Prevention of occupational skin disease in hairdressers. International Archives of Occupational and Environmental Health 1998;71(7):487-92.

[7] Coenraads PJ. Hand eczema. New England Journal of Medicine 2012;367(19):1829-37.

[8] Holden CA, Berth-Jones J. Eczema, lichenification, prurigo and erythroderma. In: Burns T, Breathnach S, Cox N, et al. eds. Rook's Textbook of dermatology. $7^{\text {th }}$ edn. Oxford: Blackwell 2004:699-754.

[9] Guin JD, Franks H. Fingertip dermatitis in a retail florist. Cutis 2001;67(4):328-30. 